\title{
FORMAÇÃO DOCENTE E SUBJETIVIDADE: CONSTITUINDO-SE PROFESSOR(A) DE MATEMÁTICA A PARTIR DE INTERLOCUÇÕES DESVELADAS NO PIBID
}

\author{
FRANCISCO JOSÉ DE LIMA \\ Instituto Federal de Educação, Ciência e Tecnologia do Ceará (IFCE) \\ Campus de Cedro \\ $<$ franciscojose@ifce.edu.br $>$
}

DOI: 10.21439/conexoes.v10i4.993

\begin{abstract}
Resumo. Neste texto, procura-se refletir sobre iniciação e desenvolvimento profissional para o exercício da docência, a partir de pressupostos teóricos e dados empíricos oriundos de memórias de licenciandos em Matemática, vivenciadas no Programa Institucional de Bolsa de Iniciação à Docência (PIBID), política pública educacional que se fundamenta no princípio da ação-reflexão-ação como referencial capaz de desenvolver competências que contribuirão com o fazer do professor. Faz-se considerações sobre a aprendizagem da docência, evidenciando o PIBID como espaço marcado por vivências e aproximação da prática, as quais permitem apropriação e elaboração de saberes científico-profissionais relativos ao chão da escola e ao fazer docente na formação inicial e constituição do professor de Matemática. O exercício analítico das narrativas revelou a perceptibilidade dos licenciandos, bem como os sentidos e os significados de diferentes interlocuções ocorridas no programa, as quais se caracterizam por desafios, tensões, expectativas e marcas subjetivas, capazes de permitir ao futuro professor depreender que constituir-se professor é uma travessia marcada por momentos de aprendizagens, dificuldades, avanços, retrocessos, rupturas e descontinuidades.
\end{abstract}

Palavras-chaves: iniciação à docência; vivência; experiência; docência; chão da escola.

Abstract. In this text, we will try to reflect on beginner and professional development to the Office of teaching, from theoretical and empirical data from memories of licenciandos in mathematics, experienced in Institutional Scholarship Program Introduction to Teaching (PIBID), public educational policy that is based on the principle of action-reflection-action as a reference able to develop skills that will help with the making of professor. Do some considerations about learning teaching, showing the PIBID as space marked by experiences and practical approach, which allow ownership and development of scientific-professional knowledge relating to the ground of the school and teacher in initial formation and Constitution of the math teacher. The analytical exercise of the narratives revealed the perceptibility of the licenciandos, as well as the senses and meanings of different dialogue that occurred in the program, which are characterized by challenges, tensions, expectations and subjective, capable of enabling the future teacher assume that constitute teacher is a crossing marked by moments of learning, difficulties, advances, setbacks, ruptures and discontinuities.

Keywords: introduction to teaching; experience; experience; teaching; ground school. 
FORMAÇÃO DOCENTE E SUBJETIVIDADE: CONSTITUINDO-SE PROFESSOR(A) DE MATEMÁTICA A PARTIR DE INTERLOCUÇÕES DESVELADAS NO PIBID

\section{INTRODUÇÃO}

Nas últimas décadas a formação de professores tem se constituído em um campo de investigação bastante fecundo, despertando o interesse de estudiosos e pesquisadores que, de alguma maneira, se propõem a analisar, refletir e compreender trajetórias de formação docente, desenvolvimento de saberes e embates presentes nos espaços de formação (TARDIF, 2002; ANDRE 2010; BARRETO, 2010, CUNHA, 2013).

Neste trabalho, pretende-se propor reflexões sobre formação e desenvolvimento profissional para o exercício da docência, a partir de interlocuções vivenciadas no Programa Institucional de Bolsa de Iniciação à Docência (PIBID), como uma das reformas para educação na última década, que "elege o princípio metodológico da ação-reflexão-ação como referencial teórico para desenvolver competências na atuação docente" (BRAZ; RUIZ, 2013).

Nesta perspectiva, formar professor é experimentar constantes desafios, pois a formação inicial se caracteriza como um espaço de construção, onde o futuro professor começa a tecer os fios condutores da profissão, compreendidos por bases teóricas, práticas, epistemológicas e didáticas que permitirão aproximação com a docência, como futuro campo de atuação.

Nestes termos, a busca inicial da formação docente deve sustentar-se em elementos teóricos e práticos que permitam ao futuro professor refletir sobre a docência e suas condições, sobretudo sobre os saberes necessários para o desenvolvimento da prática docente, tomando o fazer diário, a experiência vivida como um espaço de análise e investigação, capaz de contribuir para a melhoria do trabalho do professor.

Situada neste cenário, a formação e a aprendizagem da docência, especialmente para o ensino de matemática deve assentar-se na prática revestida de concepções que envolvam os valores e a história de vida do professor, (re)construindo um movimento contínuo a partir do presente para delinear sua prática futura. Assim, a formação do professor na perspectiva do profissional reflexivo aponta para uma nova epistemologia da prática, caracterizada pela mudança da conceitualização prática da sua formação, como do processo de seu desenvolvimento prático.

Com isso, a formação inicial docente deve ser organizada de modo que os futuros professores possam desenvolver competências para o desempenho profissional, não consistindo em um treinamento para aprender técnicas e métodos, mas subsidiando os futuros professores no seu desenvolvimento e autonomia profissional.

O texto está organizado em três sessões. No primeiro momento, faz-se considerações sobre a iniciação e a aprendizagem da docência. Na sequência, ressaltase o PIBID como espaço de vivências e aproximações da docência e destaca-se os procedimentos metodológicos, caracterizando o campo e os sujeitos da pesquisa. Por último, discute-se aspectos teóricos e dados empíricos de bolsistas do PIBID, compreendendo o constituirse professor de Matemática nas tramas do programa.

\section{ORQUESTRANDO CONSIDERAÇÕES SO- BRE A INICIAÇÃO E A APRENDIZAGEM DA DOCÊNCIA}

A literatura educacional das últimas décadas tem destacado enfaticamente a formação docente como um processo contínuo e organizado de aprendizagens que tem por finalidade a promoção do desenvolvimento profissional docente, para ensinar e aprender como princípio de sua atuação que deve se prolongar por toda a carreira (GARCIA, 1999).

As bases epistemológicas do campo da formação de professores têm motivado e disseminado, cada vez mais, estudos sobre a docência, seus embates e dilemas. As pesquisas que se reportam ao início da docência têm se destacado e ganhado espaço na produção acadêmica, apresentando reflexões sobre as primeiras experiências na profissão, que se constituem de expectativas, frustrações, aprendizagens e tensões.

Estudos realizados em diferentes contextos revelam a importância da investigação sobre a iniciação na carreira docente, despertando para a necessidade de compreender a transição de estudante para professor, a confrontação com a realidade profissional, os primeiros contatos com a escola, o papel destinado ao profissional docente, o domínio do conteúdo e o embate inicial com a prática de ensino no cotidiano da sala de aula, caracterizada por sua complexidade e imprevisibilidade, são aspectos que marcam a iniciação profissional docente (HUBERMAN, 1992; GARCIA, 1999, GARCIA, 2006, MARIANO, 2005, NONO; MIZUKAMI, 2006).

É importante mencionar, também, as expectativas e frustrações relacionadas a educação e a realidade vivida pelas escolas, elucidando as dificuldades para administrar a sala de aula e, principalmente as condições objetivas de trabalho do professor. Esses aspectos acabam fazendo parte das vivências do professor nos anos iniciais da carreira, descortinando "as contradições presentes na realidade educacional e escolar" (MARTINS; PAPI, 2010).

No que diz respeito às experiências vividas no exercício da docência nos anos iniciais, Garcia (2006) afirma que: 


\section{FORMAÇÃO DOCENTE E SUBJETIVIDADE: CONSTITUINDO-SE PROFESSOR(A) DE MATEMÁTICA A PARTIR DE}

INTERLOCUÇÕES DESVELADAS NO PIBID

\begin{abstract}
Los primeros años de docencia no sólo representan un momento de aprendizaje del "oficio" de la enseñanza, especialmente en contacto con los alumnos en las clases. Significan también un momento de socialización profesional. Es durantes las prácticas de enseñanza que los futuros profesores empiezan a conocer la "cultura escolar" (Kennedy, 1999). Pero es durante el periodo de inserción profesional cuando esta socialización se produce con mayor intensidad. En este momento, los nuevos profesores aprenden e interiorizan las normas, valores, conductas, etc., que caracterizan a la cultura escolar en la que se integran. (GARCIA 2006
\end{abstract}

Contribuindo com a discussão, Nono e Mizukami (2006) destacam que os anos iniciais de profissão "são decisivos na estruturação da prática profissional e podem ocasionar o estabelecimento de rotinas e certezas cristalizadas sobre a atividade de ensino que acompanharão o professor ao longo de sua carreira".

Assim, os anos iniciais na profissão se constituem em um período de tensões e aprendizagens intensivas sobre o ofício docente, permitindo ao professor iniciante, vivenciar a cultura escolar e suas nuances, bem como adquirir/desenvolver conhecimento profissional da docência. Desse modo, o início da docência é marcado por momentos de transformações e dificuldades, os quais marcarão a carreira e influenciarão nas características apresentadas pelo professor ao longo da mesma. (CORRêA, 2013).

Neste contexto, a aprendizagem da docência vai desenhando-se a partir de experiências e práticas que se constituem por tentativas, medos, incertezas e o desafio de aprender a docência a partir dos erros e acertos alcançados no decorrer de ações pedagógicas realizadas, resultando em experiências que se consolidam em saberes que "não se encontram sistematizados em doutrinas ou teorias" constituindo a cultura da ação docente (TARDIF, 2002, p.49).

A ação docente cotidiana permite ao professor lidar com os limites e as possibilidades da profissão no contexto onde está sendo exercida, não excluindo as condições de trabalho que pode configurar-se como fator de sucesso ou insucesso da prática profissional e, consequentemente da aprendizagem da docência a partir do exercício da profissão, compreendendo que toda prática docente manifesta crenças, valores e concepções sobre o mundo, o ser humano, a escola e o processo de ensinoaprendizagem.

O professor iniciante, em sua prática pode tender, ainda que inconscientemente, a repetir de maneira acrítica a postura de professores experientes (MARIANO 2005). Tomar como influência as práticas de professores da educação básica pode ser a referência para o percurso profissional inicial, na tentativa de corresponder às expectativas da escola e da comunidade onde se encontra situado.

Desse modo, a adesão por uma postura em sala de aula pode ser influenciada por vivências do tempo de aluno, principalmente as recordações de professores que dominavam os conteúdos, que atuavam com autonomia, mantendo a disciplina e a organização da sala de aula, que cobravam com rigor os alunos, insistindo diariamente por melhorias na aprendizagem e aqueles que diversificavam a metodologia de ensino, eram criativos, os quais desenvolviam diferentes estratégias de ensino no contexto da sala de aula. Entretanto, as lembranças de professores, cujas ações práticas se distanciam dos aspectos mencionados acima, também podem contribuir com a formação da identidade profissional, uma vez que, suas ações práticas despertaram para o que não deveria ser feito em sala de aula.

\section{COMPREENDENDO O PIBID COMO ES- PAÇO DE VIVÊNCIAS E APROXIMAÇÕES DA DOCÊNCIA}

O Programa Institucional de Bolsa de Iniciação à Docência (PIBID) é um programa do Ministério da Educação (MEC), gerenciado pela Coordenação de Aperfeiçoamentode Pessoal de Nível Superior (CAPES) que tem por finalidade incentivar o aperfeiçoamento e a valorização da formação de professores para a Educação Básica.

O programa concede bolsas a alunos de licenciatura participantes de projetos de iniciação à docência desenvolvidos por Instituições de Educação Superior em parceria com escolas de Educação Básica da rede pública de ensino. Os projetos devem promover a inserção dos estudantes no contexto das escolas públicas desde o início da sua formação acadêmica para que possam desenvolver atividades didático-pedagógicas sob orientação de um docente da licenciatura e de um professor da escola (BRASIL, 2013).

$\mathrm{Na}$ iniciação à docência, os primeiros contatos com o universo de atuação futura, causam no licenciando, uma série de expectativas e aspirações, que podem conduzir o futuro professor a questionar: Como se comportar diante de uma sala de aula? O que falar para os alunos? Qual linguagem utilizar? O que propor à turma? Quais metodologias são adequadas para os conteúdos a serem trabalhados? Como fazer a reelaboração conceitual dos conteúdos matemáticos para oportunizar a aprendizagem dos alunos?

O PIBID como possibilidade de aprendizagem da docência, deve incitar o diálogo na perspectiva do embate reflexivo sobre experiências iniciais relacionadas à 


\section{FORMAÇÃO DOCENTE E SUBJETIVIDADE: CONSTITUINDO-SE PROFESSOR(A) DE MATEMÁTICA A PARTIR DE}

INTERLOCUÇÕES DESVELADAS NO PIBID

prática docente, permitindo ao professor em formação inicial, externar suas expectativas frente ao seu campo de atuação, território que o mesmo ainda não transitou e necessita ouvir professores da Educação Básica, depreendidos como professores experientes, que possam subsidiar seu fazer com elementos teóricos e práticos, os quais poderão contribuir para a sua atuação pedagógica.

Como espaço de reflexão sobre a docência, o PIBID se constitui e se compõe de docências (Licenciandos em formação inicial e Professores da Educação Básica) propiciando formas de pensar, agir e atuar como professor, produzindo ideias em educação para o ensino e a aprendizagem matemática. Dentre os objetivos do PIBID, destaca-se sua contribuição para a articulação entre teoria e prática necessárias à formação dos docentes, elevando a qualidade das ações acadêmicas nos cursos de licenciatura, inserindo os licenciandos na cultura escolar do magistério, por meio da apropriação e da reflexão sobre instrumentos, saberes e peculiaridades do trabalho docente (BRASIL, 2013).

Como é possível perceber, a qualidade da formação superior é um anseio e uma necessidade. Por esta razão deve priorizar a articulação entre teoria e prática como possibilidade capaz de se traduzir em melhoria na formação inicial de professores, superando práticas formativas permeadas por perspectivas positivistas. Esta superação pode iniciar com a integração entre universidade/instituição de ensino superior e escola de educação básica, que deverão estruturar suas relações no diálogo e na reflexão, evidenciando suas interfaces em função da formação inicial de futuros professores.

Com a inserção de licenciandos na cultura escolar é possível analisar o cotidiano escolar, observar e refletir sobre atitudes e experiências metodológicas oriundas da prática docente desenvolvida na sala de aula. Assim, o PIBID propicia a instrumentalização para tratar adequadamente os problemas relacionados ao processo de ensino-aprendizagem podendo motivar os futuros professores ao exercício da docência, contribuindo para a elevação da qualidade da educação básica como uma de suas finalidades basilares.

A interação e o diálogo estabelecidos entre coordenadores, supervisores e licenciandos produzem um movimento ativo de formação recíproca e crescimento contínuo, em sentido duplo, em que tanto a escola básica quanto a universidade retroalimentam a relação entre teoria e prática, aprendendo e ensinando ao mesmo tempo (CANAN, 2012). Desse modo, pode-se afirmar que a dinâmica de desenvolvimento do PIBID elege o diálogo como caminho que deve ser trilhado constantemente pelos protagonistas do programa, potencializando troca de experiências, formação recíproca e crescimento contínuo.

Nesta perspectiva, as tramas e interlocuções desveladas pelo PIBID, assentam-se nas contribuições de Vygotsky(1896-1934) e Bakhtin (1895-1975), teóricos do início do século XX que mais favoreceram a dimensão interativa da atividade humana, cujo fundamento da natureza dialógica da experiência humana é marcado como elemento essencial para compreensão e transformação da realidade (FERNANDES; CARVALHO; CAMPOS, 2012).

A partir da relação dialógica arrolada em diferentes atividades desenvolvidas no programa, coordenadores, professores supervisores e licenciandos vão formandose e constituindo-se subjetivamente no contexto das relações estabelecidas, observando os modelos de professores apresentados nas práticas desenvolvidas e formas de organização do trabalho docente, os quais vão sendo introjetados e ressignificados, numa dinâmica que implica tensões, embates, representações e rupturas (CRUZ, 2013).

Assim, o princípio formativo expresso pelo PIBID, firma-se na dialogia como espaço capaz de produzir/construir conhecimentos e habilidades sociais num processo de interação, pressupondo convergência e divergência de ideias e "contradições constitutivas de diferentes vozes sociais que nele se manifestam" (FONTANA; SILVA, 2009, p. 38). Desse modo, o movimento polifônico entre coordenadores, professores supervisores e licenciandos deve ser depreendido como ocorrência transitória e singular, cujas consequências serão decisivas para a apropriação subjetiva das construções culturais, sejam elas científicas, artísticas ou advindas da experiência (FERNANDES; CARVALHO; CAMPOS, 2012).

Essa interlocução pode favorecer a formação docente, que consiste em "processos de formação inicial ou continuada, que possibilitam aos professores adquirir ou aperfeiçoar seus conhecimentos, habilidades, disposições para exercer sua atividade docente, de modo a melhorar a qualidade da educação que seus alunos recebem" (GARCIA, 1999, p.26). Assim, o PIBID deve contribuir para o desenvolvimento profissional docente tanto dos acadêmicos bolsistas do curso de licenciatura em matemática, como dos professores supervisores das escolas parceiras e dos coordenadores institucionais do programa.

Nos momentos de estudo e discussão coletiva sobre a aprendizagem da profissão docente, se deve destacar o saber do professor como um "saber plural, formado de diversos saberes provenientes das instituições de formação, da formação profissional, dos currículos e da prá- 
tica cotidiana" (TARDIF, 2002, p.54) e estes, se apresentam como indispensáveis para o exercício da prática docente em matemática.

Esta confrontação inicial no PIBID apresentará ao licenciando, que a profissão docente se constitui de prazeres, desprazeres, desafios inúmeros e variados e a necessidade de aprender continuamente para melhor desenvolver sua prática. Perceberá também que ao longo da sua vida, o professor vai se tornando mais experiente, com maior desenvoltura para enfrentar os dilemas da profissão, porém, não significa que o mesmo não tenha problemas.

A proposição de ações, experiências e práticas docentes devem articular teoria e prática com a realidade local da escola, gerando a integração de ambientes formativos que permitam ao futuro professor experimentar as nuances da realidade escolar, as quais enfrentarão depois de formado. Neste sentido a inserção no cotidiano da escola e o diálogo estabelecido entre os protagonistas do PIBID, devem voltar-se para as múltiplas facetas do dia a dia escolar, realçando a investigação e a pesquisa como caminhos capazes de conduzir à resolução de situações e a inovação na prática de ensino.

Portanto, o PIBID como política pública de formação e valorização da docência, pode potencializar a formação de professores respaldada no trabalho da escola e na vivência de casos concretos, realizada com a combinação do conhecimento teórico e metodológico dos professores das instituições de ensino superior e o conhecimento prático e vivencial dos professores das escolas de educação básica.

\section{PROCEDIMENTOS METODOLÓGICOS: CA- RACTERIZANDO O CAMPO E OS SUJEI- TOS DA PESQUISA}

As narrativas têm sido uma forma de investigação bastante recorrente no campo da formação de professores. Deste modo, o estudo se constituiu de diálogos entre literatura pertinente, legislação oficial e conteúdo de depoimentos de bolsistas do PIBID Subprojeto Matemática do IFCE campus de Cedro - professores em formação inicial.

O subprojeto em que atuam se concretiza por meio de parceria entre IFCE, CAPES e as escolas básicas da rede estadual situadas em três municípios (Cedro, Várzea Alegre e Icó) do interior do Ceará e se configura como incentivo ao ingresso na carreira docente e valorização do magistério contando com 35 bolsistas (Dois Coordenadores de Área; Três Professores Supervisores e Trinta Licenciandos em Matemática). Desse universo, três bolsistas se propuseram a participar da pesquisa: Luíza e Alexandre ambos do $8^{\circ}$ semestre e Roberto e

\section{Valda do $5^{\circ}$ semestre.}

Para a coleta de dados pediu-se que os pesquisados fizessem um exercício de pensamento sobre suas vivências no âmbito do PIBID e registrassem suas narrativas. Como se objetivava discutir as interlocuções desveladas no programa e suas contribuições para a constituição do professor, pediu-se que discorressem a partir de dois eixos.

- No eixo 1- A inserção do bolsista na cultura escolar - destacar o(s) impacto(s), a(s) tensão(es), o(s) desafio(s) e a receptividade vivido(s) pelo bolsista ao chegar à escola;

- No eixo 2 - A aprendizagem da docência no espaço do PIBID - enfatizar a participação em monitoria de aulas e acompanhamento individual a alunos com dificuldades de aprendizagem; auxílio aos docentes em atividades didáticas; experiências de regência e suas contribuições para a aprendizagem da docência.

Os dados coletados para as discussões presentes neste trabalho foram coletados durante o semestre 2014.1 encerrado em novembro de 2014.

\section{CONSTITUINDO-SE PROFESSOR DE MA- TEMÁTICA NAS TESSITURAS DO PIBID}

O processo de análise das narrativas compreendeu a verificação dos registros dos participantes em relação à relevância das atividades desveladas no PIBID Subprojeto Matemática como espaço de interlocução e articulação entre saberes teóricos e práticos na perspectiva de ensinar e aprender a docência.

Compreendida como território de atuação profissional do professor, a docência se constitui de expectativas e dilemas, que estão intimamente relacionados ao processo de ensino e aprendizagem, ao avanço da ciência, às questões ideológicas, políticas e sociais e às condições de trabalho que poderão contribuir para o desenvolvimento do fazer pedagógico do professor.

A aprendizagem da docência não obedece um itinerário linear. É um processo que se constitui de (des)encontros e imponderabilidade, onde as situações vividas se apresentam carregadas de uma multiplicidade de significados e representações. Assim, a inserção do bolsista (futuro professor) na cultura escolar e integração na cultura docente (ANDRE, 2012), permite ao professor em formação inicial observar/vivenciar as múltiplas interfaces do cotidiano escolar, em suas dimensões administrativas, pedagógicas, jurídicas e financeiras. 


\section{FORMAÇÃO DOCENTE E SUBJETIVIDADE: CONSTITUINDO-SE PROFESSOR(A) DE MATEMÁTICA A PARTIR DE}

INTERLOCUÇÕES DESVELADAS NO PIBID

No PIBID Subprojeto Matemática, enfrentar a complexidade da profissão docente é inevitável. Isso pode causar no futuro professor, preocupações e desconforto em relação a sua atuação diante da realidade cotidiana do chão da escola, especialmente, da sala de aula. A narrativa de uma bolsista reflete esse contato inicial com a cultura escolar. Assim ela registra:

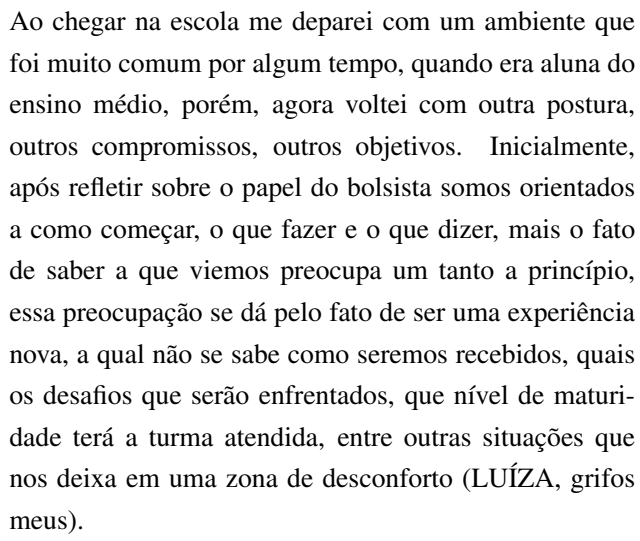

Percebe-se na narrativa da bolsista a circulação de valores constitutivos da subjetividade do professor, sendo possível verificar dilemas e tensões que atormentam o professor na iniciação à docência, deixando-o nessa zona de desconforto destacada pela participante, alargando expectativas em relação aos desafios a serem enfrentados como docente.

É possível que nesta situação, o futuro professor, se formando e se constituindo subjetivamente, se entusiasme com a docência e, para exercê-la, acaba recorrendo a modelos de professor que vivenciou ao longo de sua vida estudantil. Ao narrar que"após refletir sobre o papel do bolsista somos orientados a como começar, o que fazer e o que dizer" observa-se que, no PIBID como política pública de formação de professores, os bolsistas são introjetados em rituais para a iniciação e a constituição do ser professor a partir de diferentes interlocuções, embora a aprendizagem da profissão não aconteça linearmente, como já foi destacado e a ação docente esteja sempre submetida as condições objetivas de trabalho.

Ainda marcando a importância da iniciação à docência, Alexandre aponta que esta "permite os primeiros contatos com a escola, a fim de obter-se a noção de como se dá a realidade escolar e de que forma atuam os professores para lidar com a sala de aula". Diante da inserção, destaca como obstáculo a escolha de "uma postura adequada conforme o comportamento dos discentes na sala de aula, devido à falta de experiência no ambiente escolar" (ALEXANDRE). Em sua narrativa o participante Roberto afirma que essa inserção "per- mite uma reflexão prévia sobre a realidade escolar, que se não houvesse tal inserção, essas reflexões só seriam possíveis durante a atuação do professor".

Os trechos transcritos expressam sentidos, significados e expectativas marcados pelos primeiros contatos com a escola, revelando subjetividades (re)construídas a partir de interlocuções que se articulam na perspectiva da constituição da experiência como elemento necessário para o desenvolvimento da profissão docente. Neste contexto, o desenvolvimento está constantemente se processando e outras questões são apresentadas.

O início da docência além de manifestar-se como um momento de incertezas e tensões, se apresenta, como oportunidade para encarar desafios e superar os medos, de modo que, ao experimentar as tramas da docência, o professor iniciante teça novas relações profissionais, aprenda a partir da experiência vivida, (re)criando seu fazer docente (CORRêA, 2013).

Após destacarem a importância do programa para a iniciação à docência, os pesquisados reportam-se aos dilemas e desafios da profissão, elencando veementemente o desinteresse dos alunos pelos conhecimentos da disciplina de matemática, seguida pela falta de motivação para estar em sala de aula. Alexandre relata que

[...] o maior desafio é atrair o aluno para a sala de aula, pois, poucos têm interesse em participar do programa. Para amenizar esse problema, é sugerido que possamos inicialmente tornar as aulas dinâmicas, ou seja, uma metodologia mais atrativa e que instigue o aluno a aprender por meio da curiosidade e dos desafios.

Além do desafio relatado por Alexandre, Roberto aponta em sua narrativa que o "desinteresse" e a "desmotivação" podem ser causados por problemas estruturais, uma vez que parte dos alunos refletem "fadiga por terem assistido aula pela manhã e terem que ir à tarde para o programa, salientando que no período da tarde as ondas de calor são maiores e mais forte". Destaca ainda, a falta de transporte, uma vez que a maioria dos alunos atendidos reside na zona rural do município ou moram na cidade, porém, distante da escola, dificultando acesso, frequência, permanência e sucesso nas atividades do programa.

Em relação à percepção dos pesquisados sobre a aprendizagem da docência no contexto da iniciação à docência, estes mencionaram a relevância do programa como espaço formativo, dizendo ser o PIBID um espaço promotor de experiências que permitem a vivência de novas possibilidades, com vista à preparação para o exercício da profissão.

$\mathrm{O}$ envolvimento dos licenciandos com as atividades do programa se constitui como possibilidade de cons- 


\section{FORMAÇÃO DOCENTE E SUBJETIVIDADE: CONSTITUINDO-SE PROFESSOR(A) DE MATEMÁTICA A PARTIR DE}

INTERLOCUÇÕES DESVELADAS NO PIBID

trução de significados inerentes à docência, como fazer profissional do professor. Em sua narrativa Alexandre destaca que quando se acompanha o fazer docente, especialmente na disciplina de matemática, "observase suas ações diante das situações presentes no cotidiano escolar. Essa visão é importante na construção do aprendizado para o exercício da docência, pois enriquece o conhecimento do licenciando, fazendo ele perceber como, onde, e de que modo agir para auxiliar o aluno".

$\mathrm{Na}$ escola básica, convivendo, experimentando e compartilhando as tessituras do trabalho docente, o futuro professor de matemática vive a oportunidade de tecer reflexões e analisar o significado e a relevância do papel do professor como profissional capaz de contribuir com o processo de formação humana, transformando contextos sociais.

Nas relações desencadeadas entre professores da escola básica e licenciados, Alexandre por sua vez, pontua que "discutir ideias com professores já atuantes na área torna-se algo bastante construtivo, pois permite elaborar metodologias para empregar-se em determinadas aulas com relação a assuntos que se deseja trabalhar". Neste mesmo sentido, Luíza enfatiza a riqueza de conviver com professores da escola básica e destaca que:

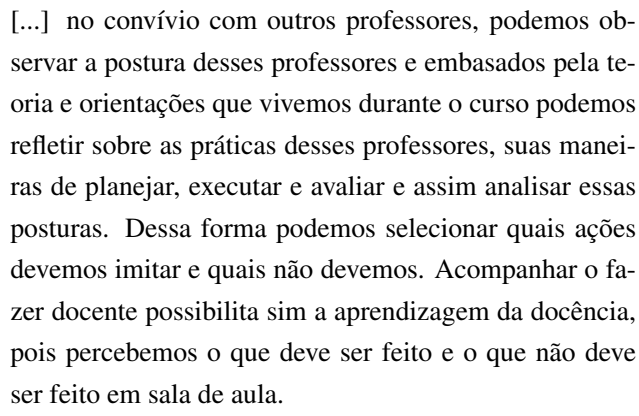

O convívio com professores da escola básica oportuniza aos licenciandos confrontação com o universo escolar, cujas manifestações auxiliam no amadurecimento do futuro professor, fazendo-o perceber que em seu fazer pedagógico, o professor, ao planejar suas ações, deve pensar estratégias e desenvolver metodologias de ensino que priorizem o desenvolvimento dos alunos, potencializando aprendizagens e estimulando a autonomia de pensamento.

Neste contexto, os saberes advindos da experiência podem propiciar dialogicidade entre o que o licenciando presencia "na prática escolar e o que sabe, estudou e aprende na interlocução com a literatura educacional e com os outros sujeitos da prática educativa." (FIORENTINI; CASTRO, 2003, p. 126), permitindo ao licenciando perceber os desafios da docência, especialmente o fazer docente face à relação pedagógica e à transmissão de conhecimentos, as dificuldades com alunos, com material didático inadequado, etc. (HUBERMAN, 1992).

[...] o PIBID possibilita ao futuro professor uma convivência real com a sala de aula, possibilitando desenvolver reflexões que são realizadas ao acompanhar o fazer docente, possibilita também a aplicação de conhecimentos adquiridos ao longo do curso, permitindo lidar melhor com os contratempos de sala de aula, estudo de material a ser utilizado em aula "planejamento", entre outros (ROBERTO)

No chão da escola, o licenciando deve perceber ainda que em sala de aula, a relação professor-aluno é uma relação hierárquica permeada pela negociação de significados, onde o professor trabalha os conteúdos de ensino e o aluno deve formar gradativamente suas ideias, despertando autonomia de pensamento.

No subprojeto PIBID Matemática do IFCE campus de Cedro, a força motriz do programa é a interação entre os sujeitos diante das ações propostas. Dentre outras ações, na escola básica, os bolsistas atuam sob o olhar e o acompanhamento do professor supervisor, realizando experiências de regência no desenvolvimento de aulas de matemática. Em sua narrativa Roberto destaca que com essa ação

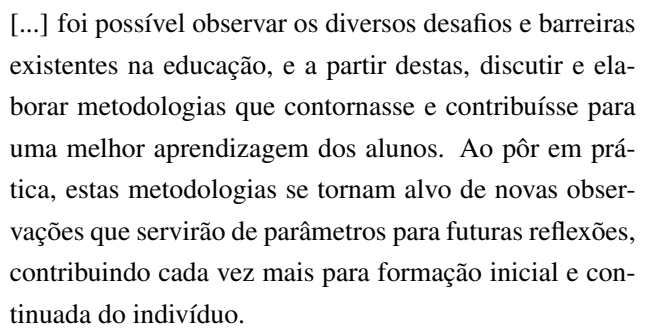

Fiorentini e Castro (2003), considera que no processo de formação inicial a reflexão deve constituir-se como parte indispensável, pois "sem reflexão, o professor mecaniza sua prática, cai na rotina, passando a trabalhar de forma repetitiva, reproduzindo o que está pronto e o que é mais acessível, fácil ou simples".

Lorenzato (2006) expressa que os saberes da experiência docente podem ser aperfeiçoados constantemente, tanto em quantidade como em qualidade. Nesta dinâmica o professor deve propor-se a refletir sobre sua prática docente diária e, até mesmo, a registrar os principais momentos de suas aulas, elencando a metodologia de trabalho, os recursos didáticos utilizados para o desenvolvimento de diferentes conteúdos programáticos, as inquietações dos educandos, pois as aulas são espaços didáticos ricos em dificuldades, perguntas interessantes, conflitos, propostas, atitudes e soluções inesperadas. 


\section{FORMAÇÃO DOCENTE E SUBJETIVIDADE: CONSTITUINDO-SE PROFESSOR(A) DE MATEMÁTICA A PARTIR DE}

INTERLOCUÇÕES DESVELADAS NO PIBID

Assim, o programa tem apontado que o modelo da racionalidade técnica não dá conta dos problemas atuais, se apresentando como oportunidade formativa que se constitui de diferentes experiências, as quais possibilitam discutir e compreender a docência por diferentes olhares e perspectivas, compreendendo que toda prática docente manifesta crenças, valores e concepções sobre o mundo, o ser humano, a escola, o ensino, etc.

Roberto destaca que o PIBID "tem promovido novas vertentes em relação ao pensar docente, pois junto aos coordenadores e professores de matemática colocam-se em discussão pontos plausíveis sobre a docência" permitindo refletir sobre "maneiras incorretas de atuação [...] visando melhorar nosso conhecimento para melhor lidar com a profissão".

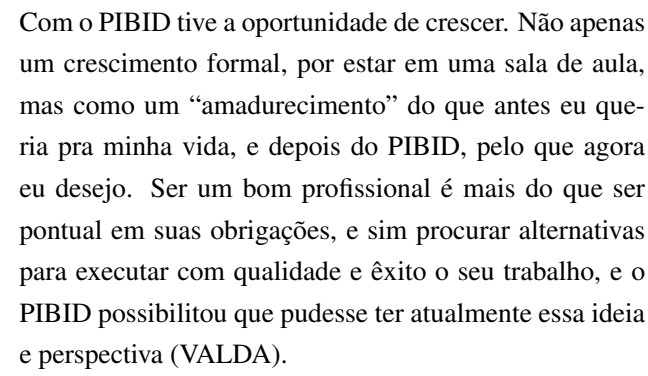

As narrativas de Roberto e Valda, embora com considerações breves e lacunares encaminha-se em direção à aprendizagem da docência e ao desenvolvimento profissional. O bolsista do PIBID, subjetivamente, ao vivenciar situações concretas do processo de ensinoaprendizagem, poderá aos poucos desenrolar o fio dialético da experiência, pois a partir de suas vivências, o futuro professor poderá aprender/desenvolver/construir estratégias matemáticas de ação que possibilitarão melhor desempenho profissional frente às demandas da atualidade.

Portanto, a aprendizagem da docência exige aproximação, compreensão e desenvolvimento de múltiplos saberes - ciências da educação, pedagógicos, curriculares e prática/experienciais (TARDIF, 2002) que são concebidos como indispensáveis para o desencadeamento do exercício da docência, especialmente, o processo de ensino-aprendizagem.

\section{CONSIDERAÇÕES FINAIS}

Imerso no ambiente do PIBID e da escola, os licenciandos podem compreender que a prática de ensino em matemática não se limita a atos formais isolados de um contexto, mas a atividades desenvolvidas diariamente por indivíduos de determinada comunidade, as quais estão inseridas numa cultura influenciada pelas pessoas, dependendo do ambiente trabalhado, da linguagem utilizada e das emoções apresentadas.

Por meio das ações realizadas no espaço do PIBID, principalmente as ações práticas desenvolvidas no chão da escola, os licenciandos devem ser estimulados a direcionar um olhar crítico às experiências vividas com professores da Educação Básica, permitindo (re)pensar estratégias de atuação, com vistas à melhoria da qualidade do ensino, à aprendizagem da docência e, consequentemente, ao desenvolvimento profissional a partir do fazer docente.

Portanto, acredita-se que os elementos presenciados e observados na escola formam um mosaico de vivências que, de alguma maneira, contribuirão para o desenvolvimento da aprendizagem inicial da docência e para a construção da identidade profissional do futuro professor como sujeito particular.

\section{REFERÊNCIAS}

ANDRE, M. Formação de professores: a constituição de um campo de estudos. Educação, Porto Alegre,, v. 33, n. 3, p. 174-181, 2010.

Polííticas e programas de apoio aos professores iniciantes no brasil. Cadernos de Pesquisa, v. 42, n. 145, p. 112-129, 2012.

BARRETO, E. S. S. Trabalho docente e modelos de formação: velhos e novos embates e representações. Cadernos de Pesquisa, v. 40, n. 140, p. 427-433, 2010.

BRASIL. Portaria no. 096, de 18 de julho de 2013 da CAPES. Regulamento do Programa Institucional de Bolsa de Iniciação à docência. http://www.capes.gov.br, 2013.

BRAZ, A. M. G.; RUIZ, C. A. L. O projeto formativo do pibid/uern. In: (Orgs.) Formação docente no PIBID / UERN. 2013.

CANAN, S. R. Pibid: promoção e valorização da formação docente no âmbito da política nacional de formação de professores. Revista Brasileira de Pesquisa sobre Formação Docente, v. 04, n. 06, p. 24-43, 2012.

CORRêA, T. Os anos iniciais da docência em Química: da universidade ao chão da escola. Dissertação (Mestrado) — PPGE/UNIMEP, 2013.

CRUZ, M. N. Investigando trabalho e formação docente na creche: contribuições de vygotski e bakhtin. Psicologia da Educação, n. 36, p. 29-40, 2013. 
CUNHA, M. I. O tema da formação de professores: trajetórias e tendências do campo na pesquisa e na ação. Educação e Pesquisa, n. 3, p. 609-625, 2013.

FERNANDES, J. F. F.; CARVALHO, M. G.;

CAMPOS, E. N. Vigotski e bakhtin: a ação educacional como projeto dialógico de produção de sentido.bakhtiniana, são paulo, 7 (2): 95-108, jul./dez. 2012. Bakhtiniana, v. 7, n. 2, p. 95-108, 2012.

FIORENTINI, D.; CASTRO, F. C. Tornando-se professor de matemática: $\mathrm{O}$ caso de allan em prática de ensino e estágio supervisionado. In: LETRAS, M. de (Ed.). Formação de professores de Matemática: explorando novos caminhos com outros olhares. Campinas: , 2003.

FONTANA, R. A. C.; SILVA, C. B. O aprendizado da docência à vozes em composição e disputa na constituição da experiência da profissionalidade. Educar, UFPR, n. 34, p. 35-52, 2009.

GARCIA, C. M. Formação de professores: para uma mudança educativa. : Porto Editora, 1999.

GARCIA, M. Políticas de insercion a la docencia: Del eslabon perdidoal puente para el desarrollo profesional docente. Bogotá, 2006. 2006.

HUBERMAN, M. O ciclo de vida profissional do professor. In: EDITORA, P. (Ed.). NÓVOA, A. (Org.) Vidas de professores. Porto: , 1992.

LORENZATO, S. Para aprender matemática. In: Autores Associados. Campinas: , 2006.

MARIANO, A. L. S. Aprendendo a ser professor no início da carreira: um olhar a partir da anped. In: Reunição Anual da Associação Nacional de Pós-Graduação em Educação (ANPEd). Caxambu: , 2005.

MARTINS, P.; PAPI, S. Professor iniciante. In: Dicionário: trabalho, profissão e condição docente. UFMG/Faculdade de Educação: , 2010.

NONO, M. A.; MIZUKAMI, M. G. N. Processos de formação de professoras iniciantes. Revista Brasileira de Estudos Pedagógicos, v. 87, n. 217, p. 382-400, 2006.

TARDIF, M. Saberes docentes e formação profissional. Atos de Pesquisa em educação, v. 6, n. 3, p. 823-830, 2002. 